\title{
Augmented Reality tools and learning practice in mobile-learning
}

\author{
Mauro Figueiredo ${ }^{1,2,3}$, José Gomes ${ }^{4}$, Cristina Gomes ${ }^{4}$, João Lopes ${ }^{3}$ \\ 1 Centro de Investigação Marinha e Ambiental \\ 2 Centro de Investigação em Artes e Comunicação \\ 3 Institute of Engineering (ISE), University of Algarve, Faro, Portugal \\ \{mfiguei, jlopes\}@ualg.pt \\ 4 Universidade Aberta \\ \{jdgomes65, ccardosogomes\}@gmail.com
}

\begin{abstract}
There are many augmented reality (AR) applications available that can be used to create educational contents for these mobile devices. This paper surveys the most popular augmented reality applications and we select AR eco-systems to be used in daily teaching activities which are user friendly, do not require programming skills and are free. Different augmented reality technologies are explored in this paper to create teaching activities with animations, videos and other information to be shown on top of interactive documents. It is presented the creation of a novel augmented reality book that was developed with teachers and students. Several examples are also presented that are used in educational activities, from kindergarten to elementary and secondary schools, to improve reading, comprehension and learning of music.
\end{abstract}

Keywords: Augmented reality, e-learning, m-learning

\section{Introduction}

Mobile computing devices allow an exponential expansion of social and participative web technologies, since they represent an increase in the ease of data access and the creation of textual and audiovisual content, even implying a situation to link at anytime and anywhere, where ubiquity is the keyword [1].

These devices have increased processing power and usability, and are accessible on a large scale, which has significantly contributed to their ease of use and at implementing innovative educational processes [2], 3] in numerous educational institutions and universities.

Many augmented reality applications are currently available. The most popular augmented-reality eco-systems are explored in this paper. We present Augmented Reality systems that can be used in daily learning activities. Such AR eco-systems must be user friendly, since they are going to be used by teachers that in general do not have programming knowledge; and open source or free for non-commercial, without any type of water marks.

This paper presents several educational activities and a novel Augmented Reality book created using free augmented reality tools that do not require 
programming knowledge to be used by any teacher. We discuss different AR ecosystems and show the most appropriate for each particular educational activity presented in this paper covering $k-12$ teaching. Marker-based and marker less augmented reality technologies are presented to show how we can create learning activities to visualize augmented information that help students understand the educational content.

This paper is organized as follows. Section 2 surveys the most common augmented reality eco-systems. In section 3 we present activities supported on marker based augmented reality for teaching music and improve reading and comprehension. Section 4 describes activities that can be used in a kindergarten and the creation of an AR book, based on marker less AR technology. Finally conclusions are presented in Section 5

\section{Augmented Reality}

Augmented Reality applications combine images, 2-D or 3-D virtual objects with a 3-D real environment in real time. Virtual computer generated and real objects appear together in a real time system in a way that the user sees the real world and the virtual objects superimposed with the real objects. The user's perception of the real world is enhanced and the user interacts in a more natural way. The virtual objects can be used to display additional information about the real world that are not directly perceived.

Ronald Azuma 4 defines augmented reality systems as those that have three characteristics: 1) combines real and virtual; 2) interactive in real time; 3) registered in $3-\mathrm{D}$.

In general, augmented reality applications fall in two categories: geo-base and computer vision based.

Geo-based applications use the mobile's GPS, accelerometer, gyroscope, and other technology to determine the location, heading, and direction of the mobile device. The user can see overlapping computer-generated images onto a real world in the direction he is looking at. However, this technology has some problems. The major problem is imprecise location which makes difficult for example the creation of photo overlays.

Computer vision based applications use image recognition capabilities to recognize images and overlay information on top of this image. These can be based on markers, such as QR (Quick Response), Microsoft tags or LLA (latitude/longitude/altitude), or marker less that recognize an image that triggers the overlay data.

There are currently many augmented reality applications and development systems for Android and iOS (iPhone Operating System) smartphones and tablets. 
We explored the following Augmented Reality systems: Wikitude 5 Layan Metai $7^{7}$ and Aurasma 8 . These are the most popular and enable the visualization of text, pictures or videos as an augmented layer.

Wikitude delivers the Wikitude World Browser for free, which is an augmented reality web browser application, and the Wikitude SDK (software development kit) for developers which is free for educational projects. However, the educational version of the wikitude SDK always displays a splash screen and the wikitude logo.

The wikitude browser presents users with data about their points of interest, which can be the surroundings, nearby landmarks or target images, and overlays information on the real-time camera view of a mobile device.

Augmented reality learning activities can be realized with the wikitude SDK. The wikitude SDK can be used to display a simple radar that shows radarpoints related to the location based objects. It is also possible to recognize target images and superimpose 2D or 3D information on top of them. The developer can also combines image recognition and geo-base augmented reality. However, the building of these capabilities using the wikitude SDK requires programming knowledge.

Layar has the Layar App, an augmented reality web browser, and the Layar Creator, which is a tool for creating interactive printing documents. With the Layar Creator it is easy to make an interactive document for a teaching activity. There is no need to do any programming and, in this way, it does not require any developers with programming skills. The teacher can easily upload the trigger page to which he wants to associate augmented information. Marker less image recognition techniques are used and with the Layar Creator interface the teacher can easily associate a video, for example. Later, with the Layar App, the student can view, on the camera of his mobile device, the overlaied information associated to the page. These applications are both free. However, every trigger image published within the Layar's publishing environment is paid. For this reason, it is not affordable for developing interactive printing documents for teaching. Geo-location based augmented reality information is free of charge.

Metaio delivers the junaio, metaio Creator and a development SDK. Junaio is the metaio's free augmented reality browser and is free. The metaio Creator is an augmented reality tool to create and publish augmented reality scenarios and experiences within minutes. With the metaio Creator the teacher can connect 3-D content, videos, audio, and webpages to any form of printed medium or 3D map (object-based or environment-based). However this tool is paid. If a user wants to develop augmented reality applications for iOS or Android, the developer can use the metaio SDK. However, this development SDK is also paid.

Aurasma delivers the Aurasma App and the Aurasma Studio.

\footnotetext{
5 http://www.wikitude.com/

6 http://www. layar.com/

7 http://www.metaio.com/

8 http://www. aurasma.com/
} 
The Aurasma App is available for Android and iOS and uses advanced image recognition techniques to augment the real-world with interactive content such as videos, 3D objects or animations associated to trigger images or geo-based information.

The Aurasma Studio is an online platform that lets the teacher create and publish their own augmented reality information in an intuitive and user friendly environment. It is not required any programming knowledge and every teacher can easily upload trigger images that can be associated to videos, images, 3D objects or other information.

The Aurasma eco-system delivers these application for free.

In this way, as our concern is to find augmented reality eco-systems that do not require programming, that are free and easy to use for learning activities. For this reason, in the following sections of this paper we use Aurasma system which is free, do not require programming and with them teachers can prepare activities in an easy way.

\section{Creating learning activities using marker-based AR technologies}

Marker based augmented reality technologies recognize a pattern/code when a camera points at it that is used to trigger the AR content. The most common marker-based Augmented Reality implementations use Quick Response (QR) codes. There are other markers that can be used such as the Microsoft tags or the LLA (latitude, longitude and altitude).

In this section, we present several examples of using marker based augmented reality technologies to create teaching activities.

Using marker based codes for presenting additional information in a mobile device. The teacher can use QR two dimensional codes for associating information such as text, URL or any other data. Quick response codes are much more popular than the other code formats. Its main advantages is that they use open source technology and in this way they are free and always will be. There are several sites where the teacher can easily create such codes. One that can be used and is free is http://keremerkan.net/qr-code-and-2d-code-generator/.

This Website links the QR code to text, to make a phone call, to send an email, to tweet, to open google maps and many other possibilities. In practice, there is no limit, since the QR code can link to an url. In this way, using for example dropbox $\sqrt{9}$ the QR code can open sound, images or movies files that can be stored in the cloud.

Figure 1 shows an example of using QR codes to study the Portuguese author Fernando Pessoa by students of the 12 th grade. With this sheet the students can explore in the class, or at home, other materials that teachers consider to be important for them.

A disadvantage of the QR codes is that they are in general large and can take too much space, specially if they have to store too much information. When we

\footnotetext{
$9 \longdiv { \text { http://www.dropbox.com/ } }$
} 


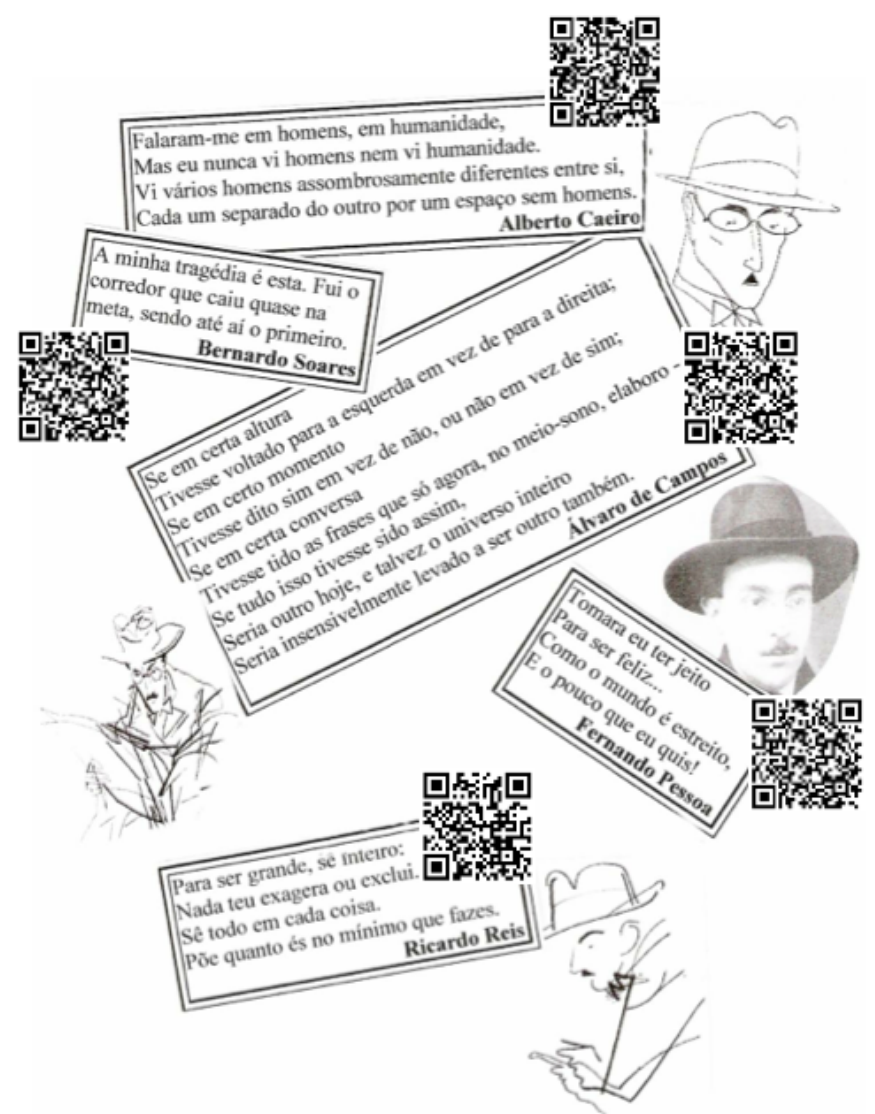

Fig. 1. Study of the Portuguese author Fernando Pessoa using QR codes to access additional materials.

want to use smaller codes that become less intrusive we can use the Microsoft tags. Reading smaller Microsoft tags are more reliable then the equivalent QR codes. The example presented in figure 2 uses Microsoft tags.

Microsoft tags are also very easy to create, requiring only the registration at the site http://tag.microsoft.com.

The example of figure 2 uses the Microsoft tags to show the answers to the different questions. We created other augmented reality documents with music sheets and we noted that the students were more interactive in the classroom, improving the learning process [5]. 


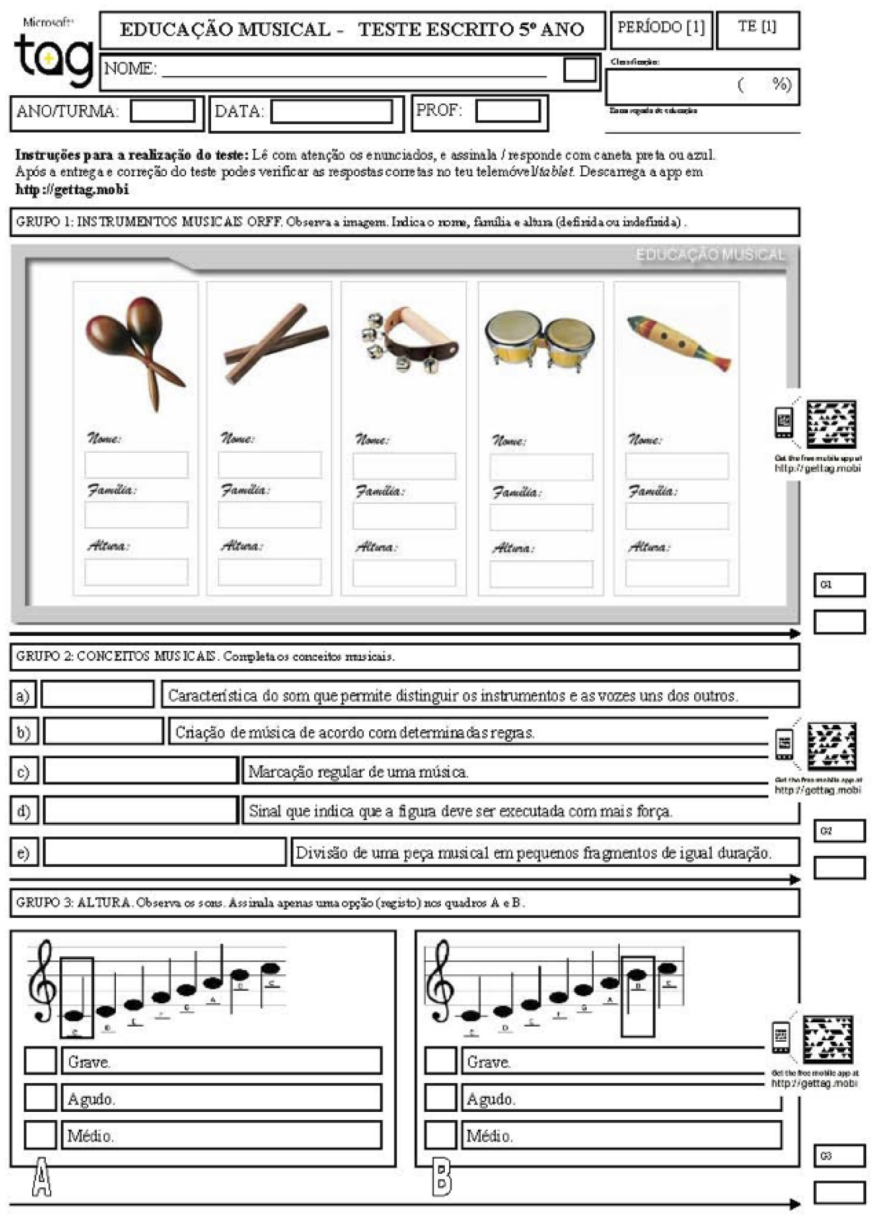

Fig. 2. Music test with Microsoft tags codes.

\section{Creating learning activity using marker less AR technologies}

In this section, we introduce the augmented reality technologies that we found more appropriate to create learning activities based on an image that triggers an animation that can be used for teaching activities in a kindergarten (subsection 4.1) or for creating an Augmented Reality book (subsection 4.2. .

\subsection{Activities for kindergarten}

In a kindergarten a childhood educator frequently reads a story to children and then make an activity about it. In this section, it is shown a form of a puzzle (fig. 3) that is shown to children after the childhood educator reads to them 


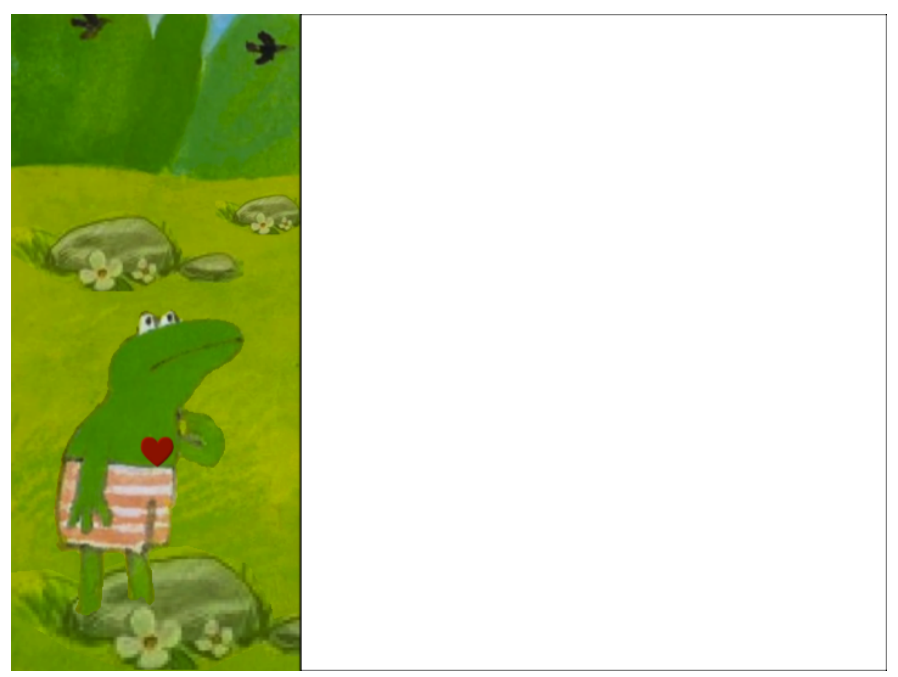

Fig. 3. Puzzle.
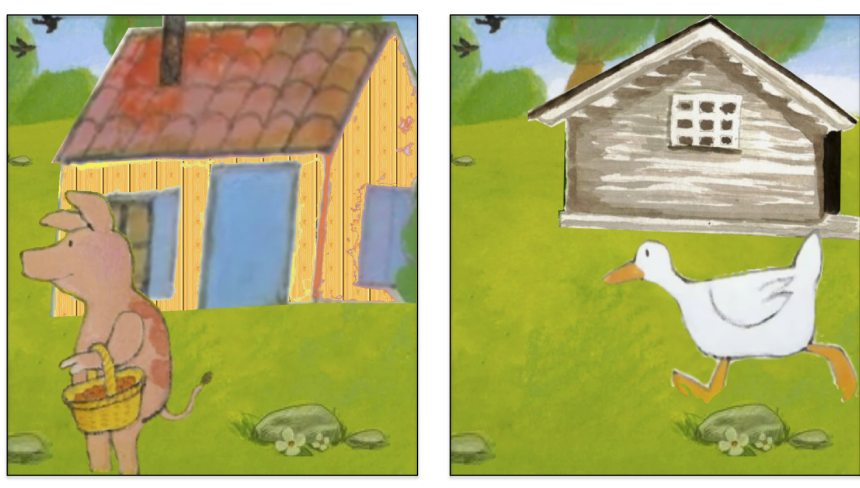

Fig. 4. Two of the possible characters that children have to choose.

the story of the "Frog and Duck". The children have to choose the appropriate character (fig. 4) to the question formulated by the childhood educator to place in the puzzle (fig. 3). Once they choose the right character, the trigger image (fig. 5) activates the associated animation that was generated with Microsoft Power Point.

The images presented in figures 3 to 5 were created from an original image from the story and edited using GIMP ${ }^{10}$ (GNU Image Manipulation Program). Although GIMP is an advanced application, it was easy to use and very useful for: i) extracting the characters with transparency from the original image and to ii) fulfill the background after removing the duck. For this purpose, we used

$1 0 \longdiv { \text { http://www.gimp.org/ } }$ 


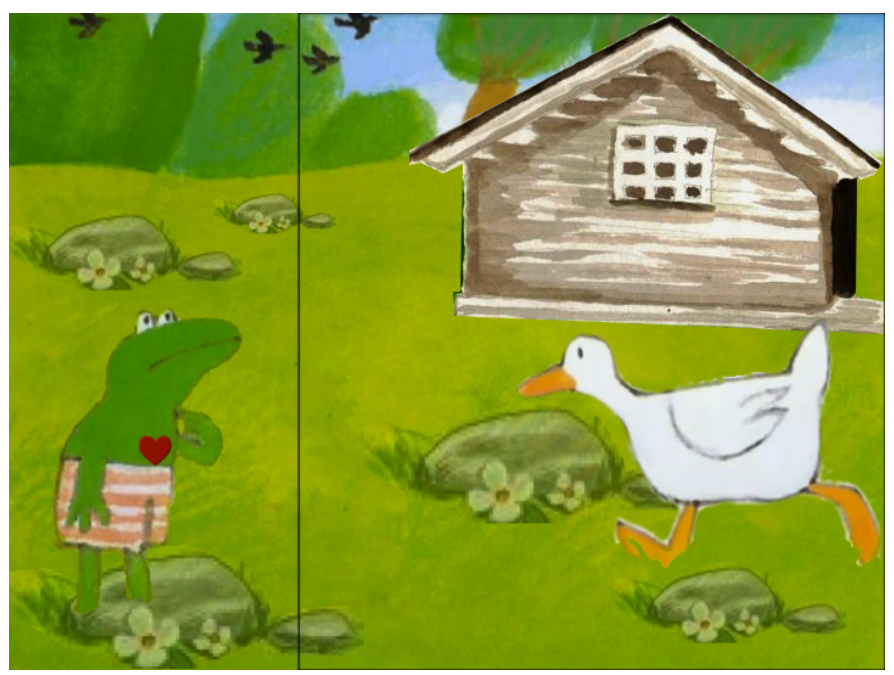

Fig. 5. Trigger image that is used to start the animation.

the GIMP Foreground Select Tool and Heal Selection which are very easy to use and yet very powerful.

After making the trigger image and the animation, it is time to use an augmented reality eco-system so that when using a mobile device it can recognize the trigger image and activate the animation.

For the recognition of marker less images we used the Aurasma eco-system which is free, does not require programming knowledge and is easy to use.

After registering to Aurasma we can access to the Aurasma Studio that begins with the step by step tutorial.

The teacher setups his augmented reality contents in Aurasma Studio with the following steps.

First, the teacher creates a channel. It is like a YouTube Channel or TV Channel, except that this is the teacher augmented reality channel and, there is no limit, the teacher can create multiple channels. In this case, we created an education channel that can be followed using the following link to subscribe http://auras.ma/s/tBkQ0. This is created once and the teacher can add multiple augmented reality contents into the same channel.

The second step is to upload the trigger image of figure 5 . The trigger image is a still image that will trigger the augmented reality contents. It is a JPEG or PNG file that in the Aurasma Studio has less than 500, 000 pixels. The one used in this example has $720 \times 540$ pixels which makes the total of 388,800 pixels. The teacher only has to give a name to the trigger image, select the file to upload and save it.

The third step is to upload the overlay content that will replace the trigger image. Overlays can include videos, images, 3D scenes or web pages. The teacher 
gives a name to the overlay content, select the file to upload and save it. It is recommended the use of MP4 video format files up to 100MB.

The final step is the aura creation. Auras are augmented reality actions images, videos or 3D animations that appear when the mobile device is pointed to a real world image or object. The auras associate the trigger image to the overlay animation and stores it to the channel created before. This information is stored in Aurasma Central. Whenever the Aurasma application is running on a mobile device it connects to Aurasma Central to download auras that the user is subscribing in a channel.

The process is simple as it was described. Compared to other augmented reality authoring tools available, this one is definitely the simplest one and is free.

\subsection{Creating an Augmented Reality Book}

At the grouping of schools of Padrão da Légua we started a project, which aimed at the integration of AR technology with the mobile-learning concept. The establishment of collaborative work between different disciplinary areas, teachers and students, were one of the main project objectives, focusing to develop an artifact with potential use in the process of teaching and learning within educational contexts. The work took the form of a book to which audiovisual elements (multimedia) were added using AR supported by the Aurasma platform that can be explored in the Aurasma Chanel/http://auras.ma/s/30BNz.

Development of interdisciplinary cooperative work The project had the support of teachers and students in the subject areas of Music Education, Visual Education, Visual Arts, Educational Resource Center and Special Education students from the school of Leça do Balio. The unifying theme chosen was the sea. The project was selected from more than sixty schools and presented in the national fourth contest Sea Kit, at the Pavilion of Knowledge in Lisbon on May 17th, 2013. The coordination of the project consisted in the allocation of tasks and work proposals for teachers and students, with the following contributions:

- Musical Education teachers and students focused their research efforts in finding songs that included ocean related elements in their lyrics or theme. That research returned a set of songs suited to play on the fipple flute. These songs were adapted to the flute tessiture and complemented with orchestral accompaniment. Finally the songs were recorded onto video to support students live play, known as play-along (fig. 6). Information about the composers, interpreters or the song itself was gathered and present in video format.

- Visual Education teachers and students researched the marine fauna and flora of the Portuguese coast, from which they produced a collection of drawings and art, using different techniques, from textured materials suited to the tactile experience to colored pencil or china ink contour. 
- The Visual Arts teachers and students produced two short movie sequences, animated according to the stop-motion technique. One was created using sequential drawings. Students draw the aquarium and the fishes to generate the animation (fig. 7). The second, the movie 'The Little Girl and The Sea Star" (fig. 8), was created using moldable plastic figures and received a sound track fully elaborated by a special education student. The movie sound track involved environment sounds recollection and audio manipulation in Audacity by the student itself, using different techniques and resources. The final video file, was produced in Movie Maker according to a storyboard depicting the scenes, planes and the audio soundtrack.

- The Educational Resources Center, contributed with a photo sequence depicting scenes from the life of Matosinho's fishermen from the past to the present day. This contribution took the form of a video with a popular sea theme related sound track.

Along the first and second period of the school year a large amount of works took shape. From these, a few were chosen according to higher quality patterns or those that meant greater effort and involvement from the students. The cooperative work established between teachers and students around a common project contributed significantly to greater involvement and motivation of everyone, extending it to the school management, the parents and the educational community.

\section{Conclusions}

The dissemination of low cost smartphones and tablets of increasing processing power makes it possible the use of mobile platforms in the classroom. In recent years surged many augmented reality applications that are available in mobile platforms.

In this paper we explored the most popular augmented reality applications. We find out the most appropriate for teaching and learning. We selected those that can be used by teachers which do not require programming knowledge and are free for educational purposes. This paper also presents several examples of augmented reality activities for the classroom.

We explored AR marker based codes using Quick Response codes and Microsoft tags in activities to study a portuguese author and for music evaluation. We prefer the smaller Microsoft tags that are better recognized than the Quick Response codes.

We created educational activities based on marker less images for kindergarten and it is presented an augmented reality book that was developed with students and teachers from the school of Leça do Balio. For this purpose, we found out that the most appropriate tool is the Aurasma application. 


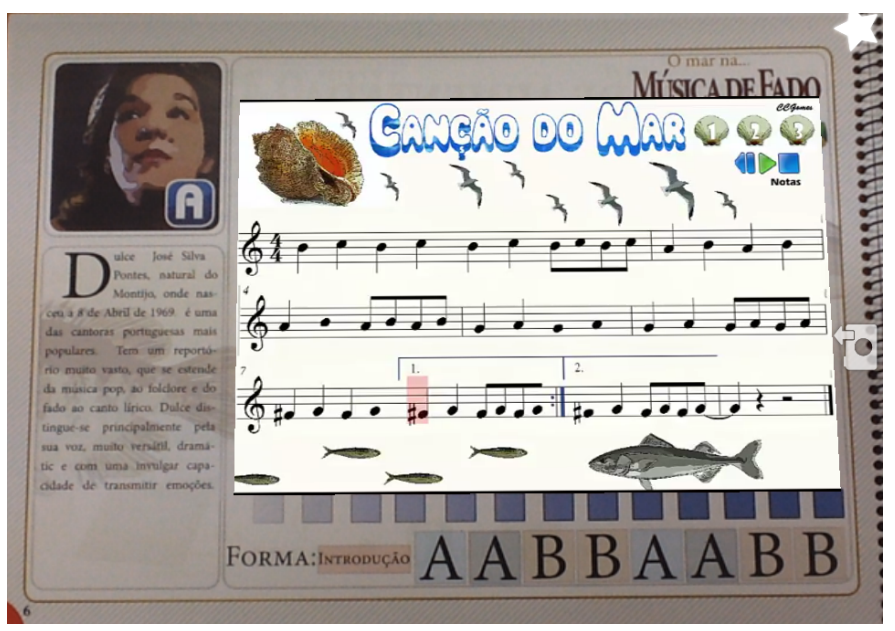

a)

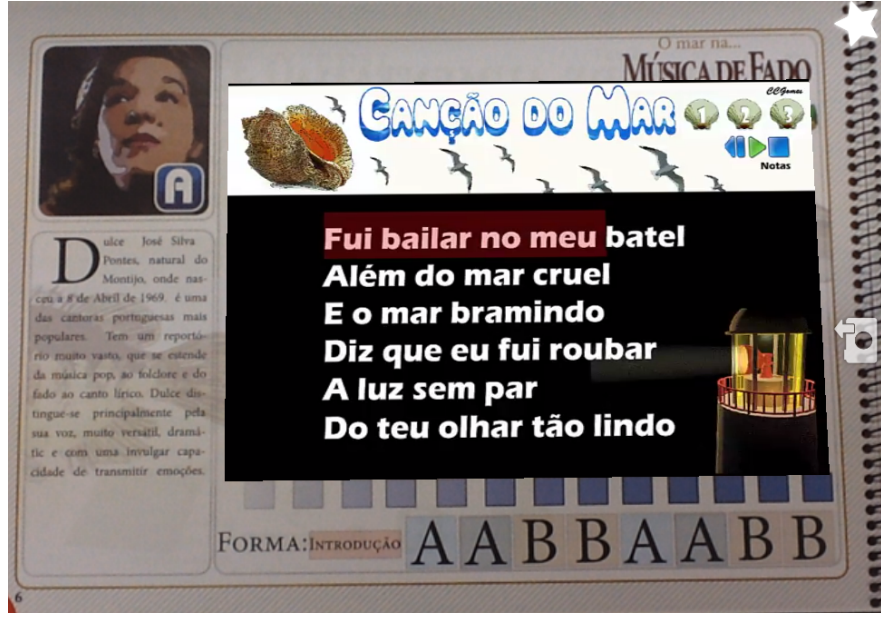

b)

Fig. 6. With a mobile device the student can follow the (a) high-lighted guitar chords; and (b) and the high-lighted play-along.

\section{References}

[1] Gmez, R.S., Lanna, L.C., i Oro, M.G.: Anlisis del entorno colaborativo creado para una experiencia de mobile learning. Teora de la Educacin: Educacin y Cultura en la Socied de la Informacin 14(1) (2013) 101-122

[2] Espinosa, R.S.C.: Percepciones de estudiantes sobre el aprendizaje mvil; la nueva generacin de la educacin a distancia. Cuadernos de Documentacin Multimedia $\mathbf{2 1}(0)$ (2010)

[3] Fernandes, G., Ferreira, C.: Desenho de contedos e-learning: Quais teorias de aprendizagem podemos encontrar? RIED: revista iberoamericana de educacin a distancia 15(1) (2012) 79-102 


\section{AQUÁRIO 02}
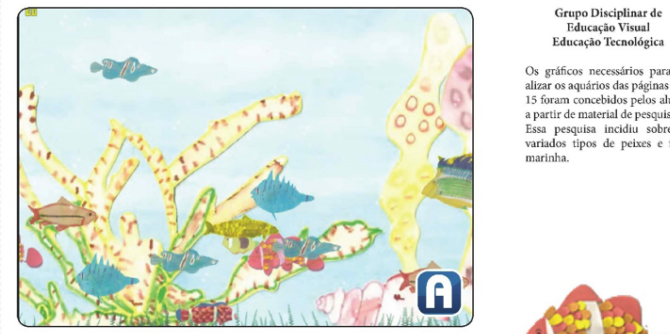

Os graficos necessarios para ne

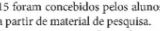

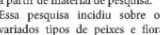

variados tipos de peixes $\mathrm{e}$ flore
marinha.

田

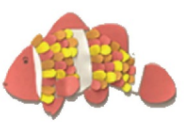

Fig. 7. Augmented Reality aquarium example.

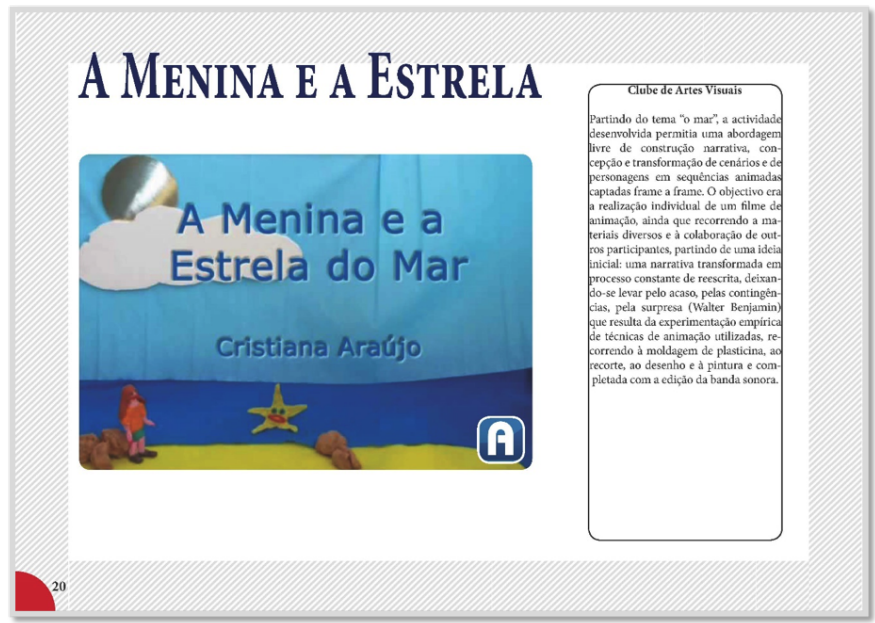

Fig. 8. Short animation movie "The Little Girl and the Sea Star".

[4] Azuma, R.T.: A survey of augmented reality. Presence: Teleoperators and Virtual Environments 6(4) (August 1997) 355-385

[5] Beauchamp, G., Kennewell, S.: Interactivity in the classroom and its impact on learning. Comput. Educ. 54(3) (April 2010) 759-766 